\title{
EN EL LÍMITE
}

\section{(IN THE LIMIT)}

José Miguel Reyes González, Arquitecto

Fecha de recepción: 13-1.92

Estudio: Bretón de los Herreros, 10

\section{RESUMEN}

El vidrio: límite tecnológico, límite físico. ¿También límite existencial?

¿Dentro o fuera?

\section{¿Soluciones extremas o soluciones mixtas?}

Arquitecturas de vidrio que nos separan o nos unen al exterior. Arquitecturas ideales, o adaptadas al medio circundante.

Diferentes gastos de energía para diferentes planteamientos. Una atmósfera terrestre en continua evolución. Diferentes geografías y metrópolis artificiales. ¿Nos veremos obligados a elegir en el límite?

Se exponen aqui diferentes arquitecturas que responden a estos distintos planteamientos.

\section{SUMMARY}

Glass: technological limits, physical limits, existential limits as well?

Inside or outside?

Extreme or combined solutions?

Glass architectures separating us from the exterior or uniting us with it? Ideal architectures or those adapted to the surroundings?

Different energy costs for different solutions. A continually developing terrestrial atmosphere. Different geographies, artificial metropolis. Will we have to face the obligation to choose within the limits?

Different architectures answering these questions are presented in this article.

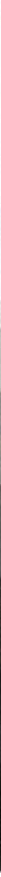


¿Dentro o fuera? Parece que este dilema estuviera siempre presente cuando hacemos a la arquitectura responsable del control del medio. ¿Cómo es ese límite, ese cerramiento, según sea la arquitectura que nos propongamos, o viceversa? Parece que existen dos opciones claras y opuestas:

- Una que se separa claramente del medio exterior y crea su propio ecosistema interno.

- Otra que, por el contrario, considera como integrante del mismo ecosistema tanto al interior como al exterior, es decir, establece una fuerte relación entre ambos.

Paradójicamente, en la construcción con vidrio -ese material que nos ha permitido, poco a poco, asomarnos progresivamente al exterior-es en donde más se aprecia esta dicotomía "aislamiento/relación".

Con el vidrio, el cerramiento se especializa hasta límites técnicos extremos. En una delgada capa de este material podemos encontrar altas cotas de resistencia mecánica, de aislamiento térmico, de polarización al paso de la luz, etc. Todas ellas propiedades que, independientemente de los agentes exteriores, nos permiten crear microclimas en el interior de nuestro cerramiento. Todas ellas propiedades que, lejos de buscar una relación con el "exterior natural" (aquel vidrio por el que en un principio nos asomábamos), por el contrario, nos aislan y nos permiten vivir en un "mundo propio" formado por cualquier "naturaleza artificial": oficina-paisaje, invernadero tropical, u oasis tecnológico.

El cerramiento, el límite, nuestra relación con el exterior se convierte en una fina y ligera capa de celofán moldeable. Surgen así volúmenes abstractos y puros: cilindros, cubos, pirámides,... de superficies tersas, teñidas, transparentes o reflectantes que, al margen del medio en que flotan, contienen en su interior sus mundos propios.

Biosfera 2

Arizona

Peter Pearce, 1991
Pero, y entre tanto..., ¿qué hay de la otra opción? De esa otra opción que considera a la arquitectura como una edificación en contacto y simbiosis con el medio en que se instala. ¿Cuál es el camino del vidrio por esa arquitectura, cuyo cerramiento reacciona ante el medio y se traba con él? Donde percepción y metamorfosis se funden en la transición. 


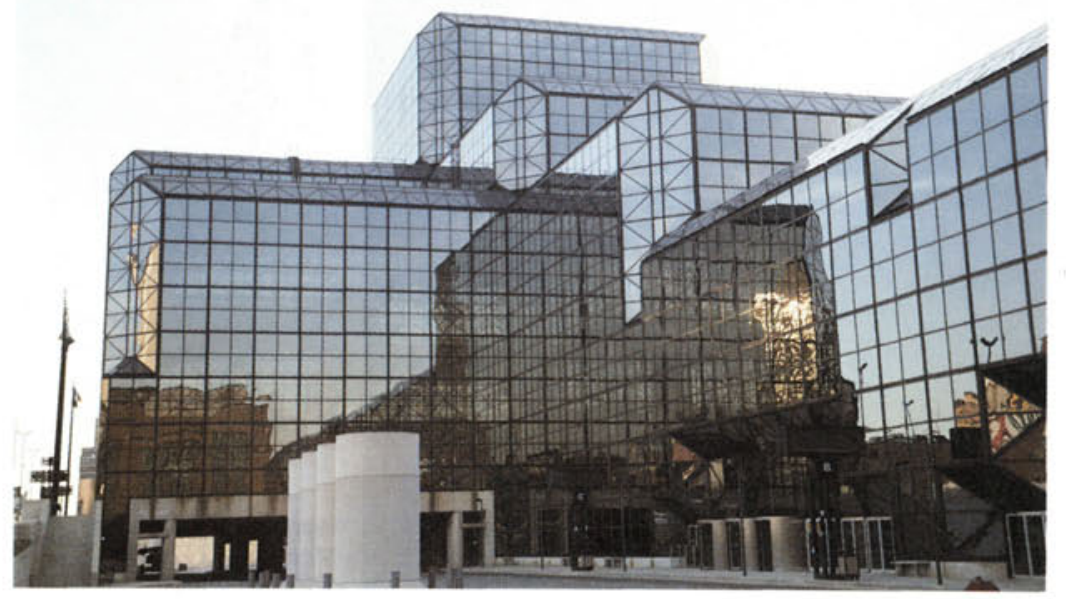

Centro de Convenciones

New York

leo Ming Pei, 1979/86

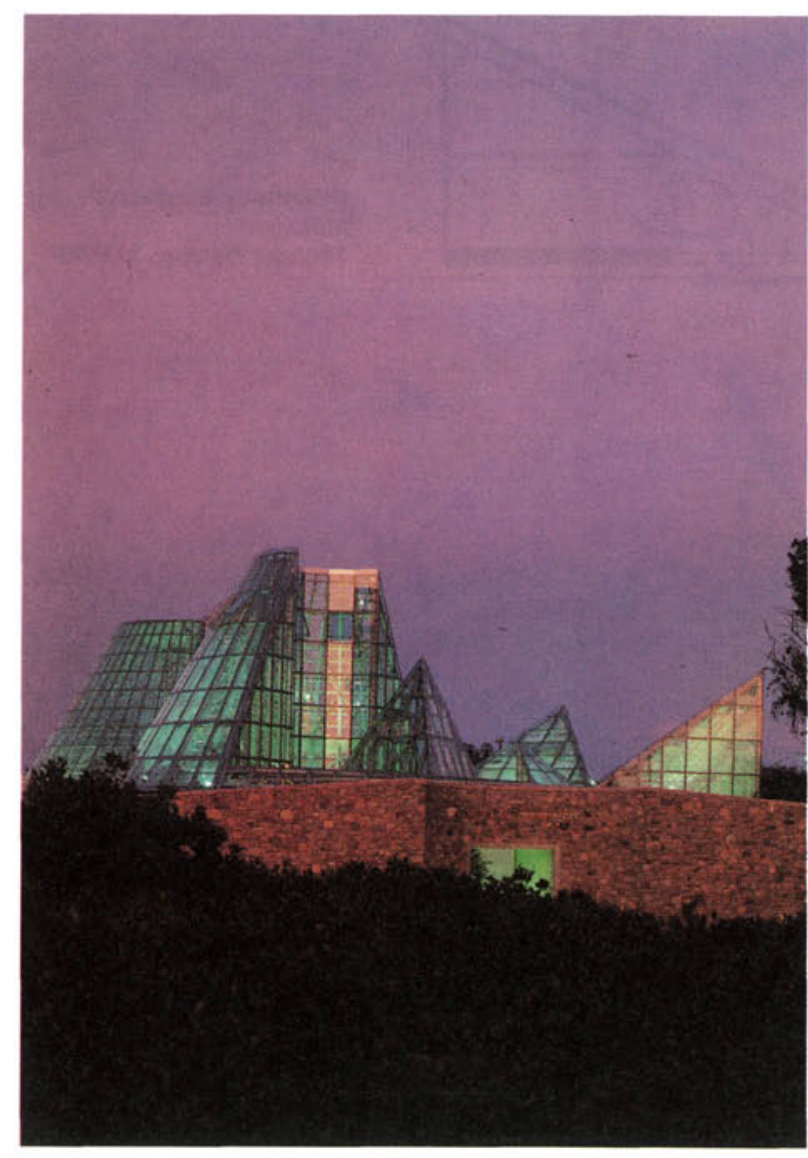

(C) Consejo Superior de Investigaciones Científicas Licencia Creative Commons 3.0 España (by-nc)

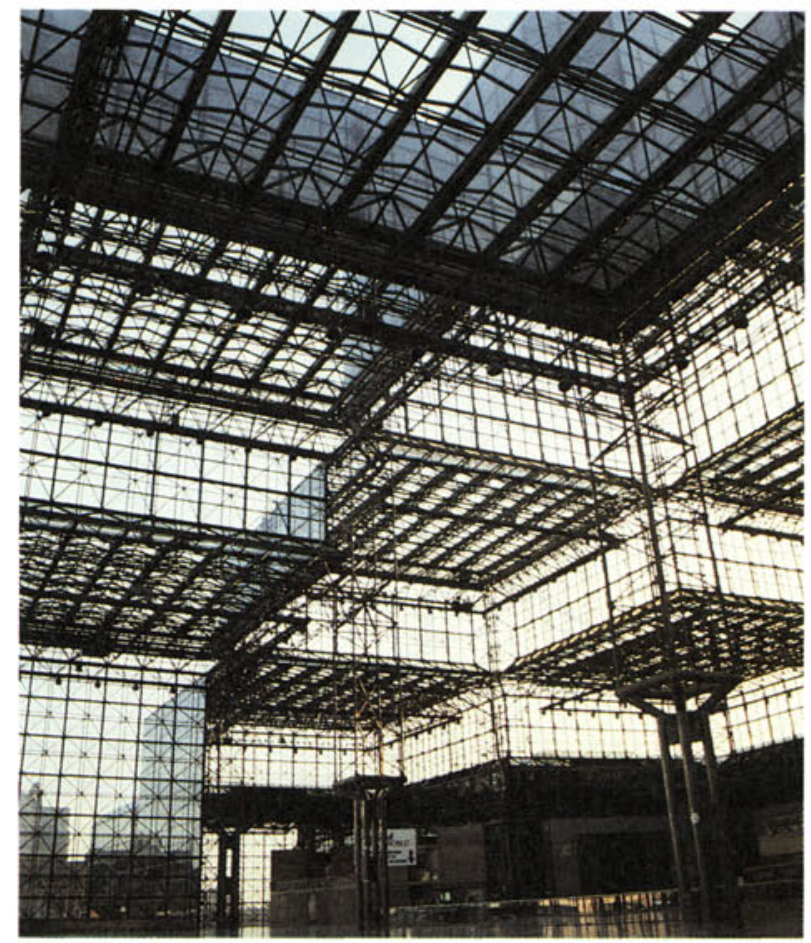

Centro de Convenciones New York

leo Ming Pei, 1979/86
Invernadero Lucille Halsall

San Antonio

E. Ambasz, 1985/87 


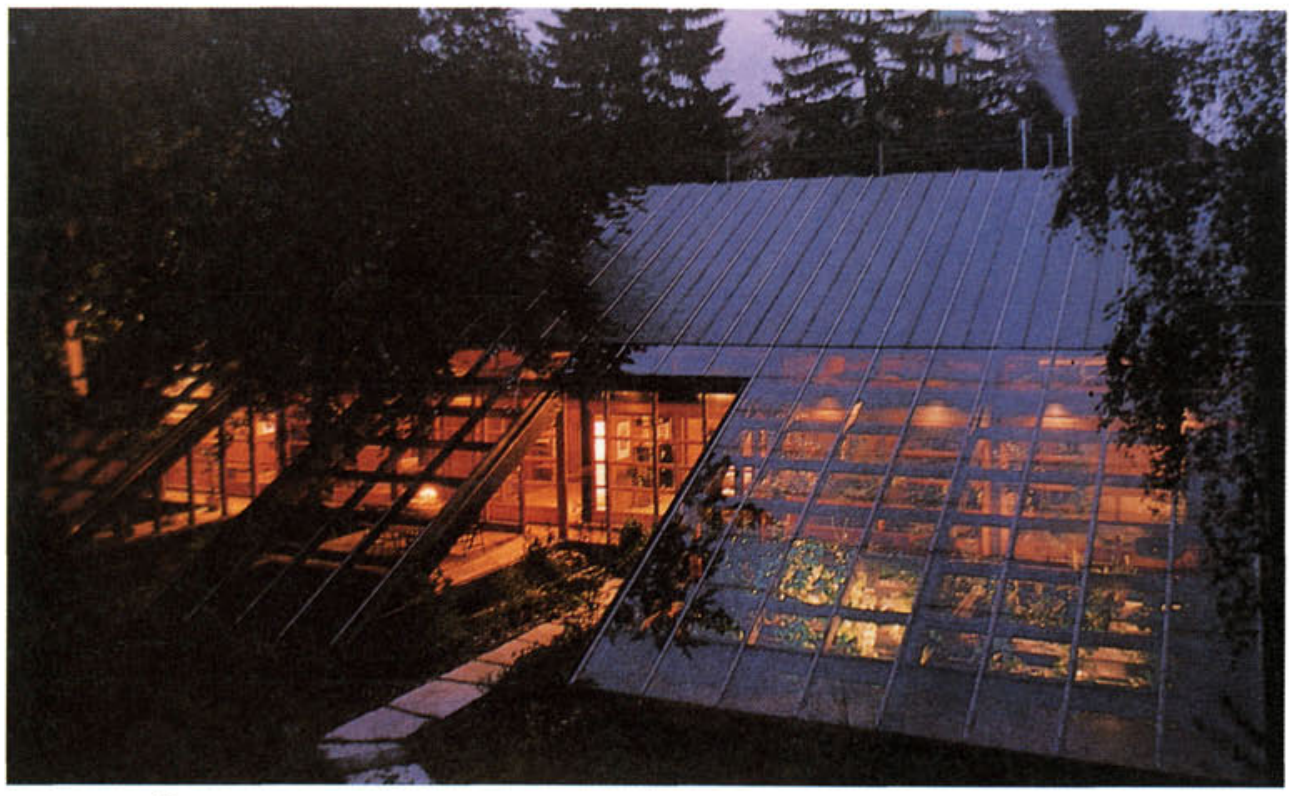

○
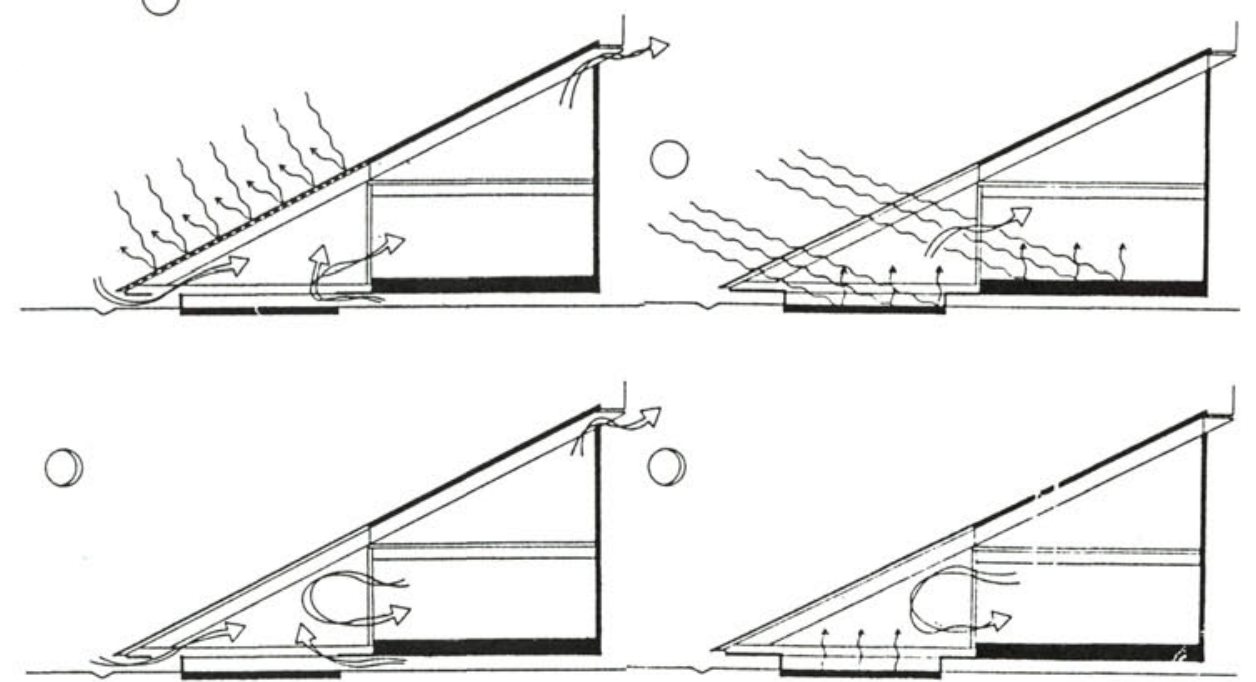

Hiver: jour, nuit
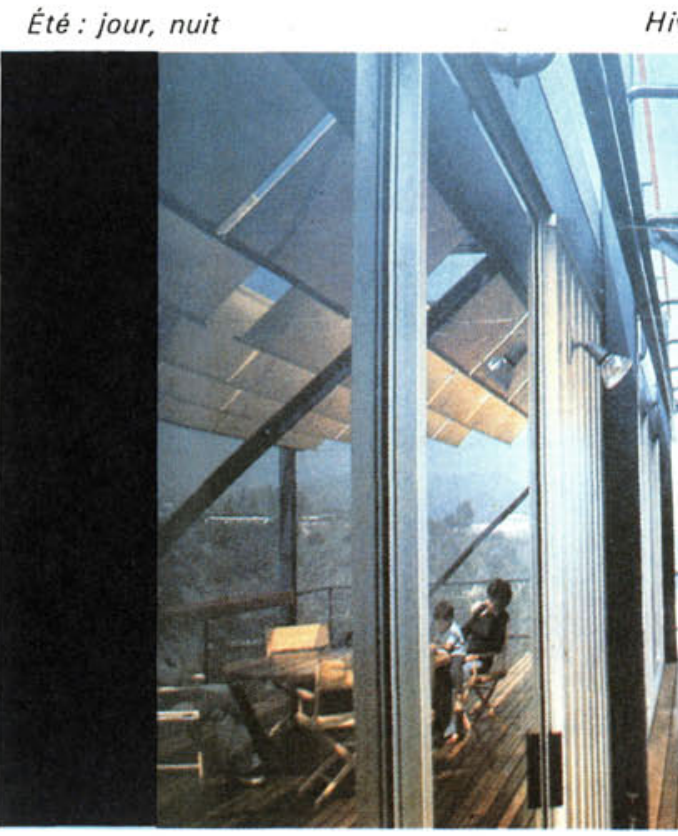

(c) Consejo Superior de Investigaciones Científicas Licencia Creative Commons 3.0 España (by-nc)
Wohnhaus Burghardt

München

Thomas Herzog, 1977/79

Wohnhaus Burghardt

München

Thomas Herzog, 1977/79
Casa T.E.S.T.

Los Ángeles, Ca.

Elmutz Shulizt, 1975/76

http://informesdelaconstruccion.revistas.csic.es 


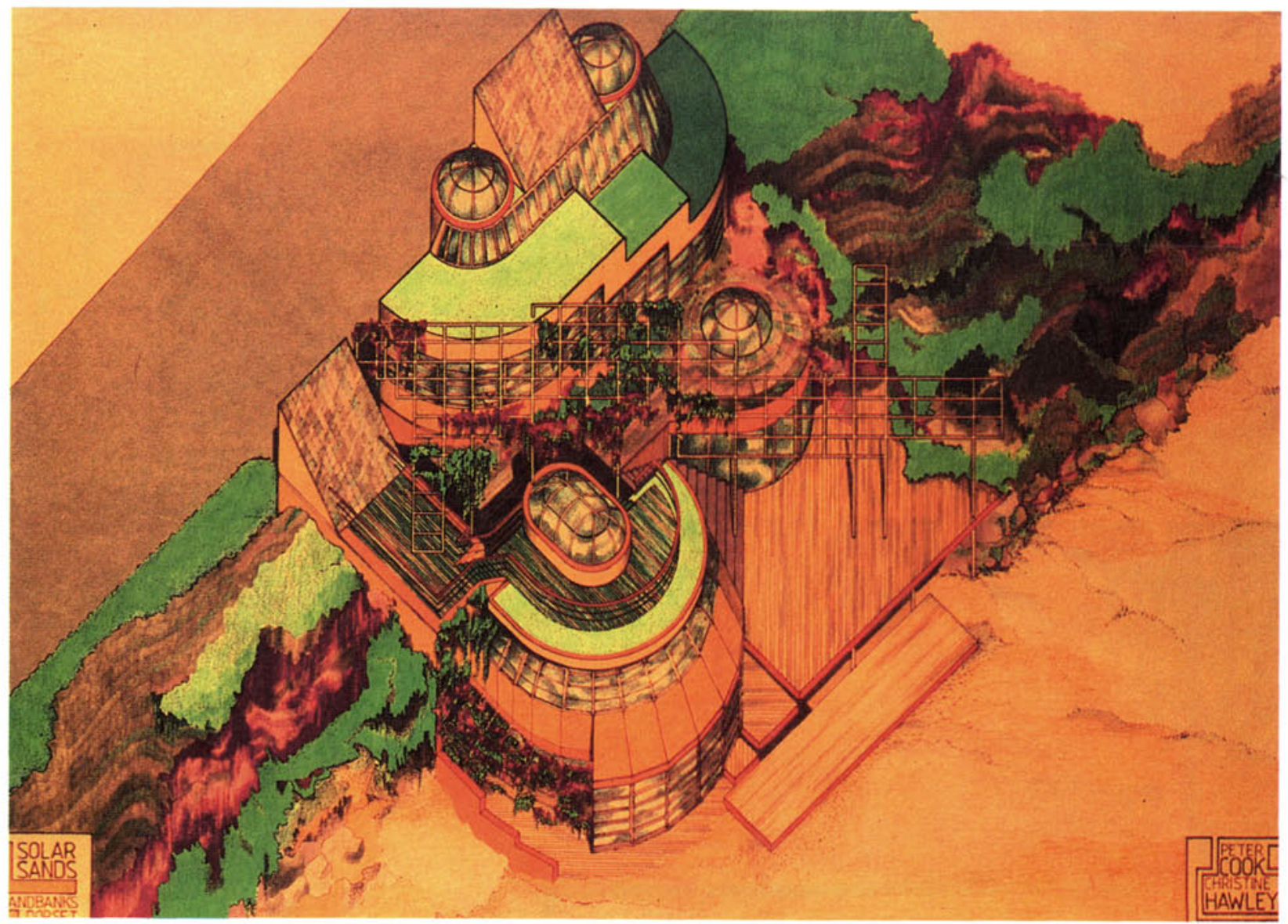

Solar Sands

Porches, balcones, galerías,... ¿Qué ha sucedido con el "grosor del muro"? ¿Cuál ha sido el espacio que ha quedado tras él, cuando es sustituido por el vidrio? Aquí nuestro límite se transforma según sea noche 0 día, invierno o verano, norte o sur. La arquitectura se gradua y nos ofrece unas cualidades y calidades donde la transparencia y ligereza no son sólo las propiedades de un material, sino las de unos espacios característicos que nos sumergen en un "continuo", cuyo único e inmenso límite es el de la atmósfera terrestre.

No se trata con estas notas de dilucidar cuál de estas dos opciones planteadas es la más o menos adecuada para esto o aquello, sino de señalar y contrastar la una frente a la otra.

Por una parte, esos volúmenes colosales, aislados, individuales sugieren la apariencia de estaciones espaciales (fortalezas cósmicas), naves isótropas capaces de navegar bajo cualquier condición atmosférica. En su interior nos ofrecen toda una serie de definiciones espaciales donde la transición entre el dentro y el fuera desaparece, la libertad espacial es enorme, todo se desarrolla en el mismo "exterior artificial": el control del medio es total.

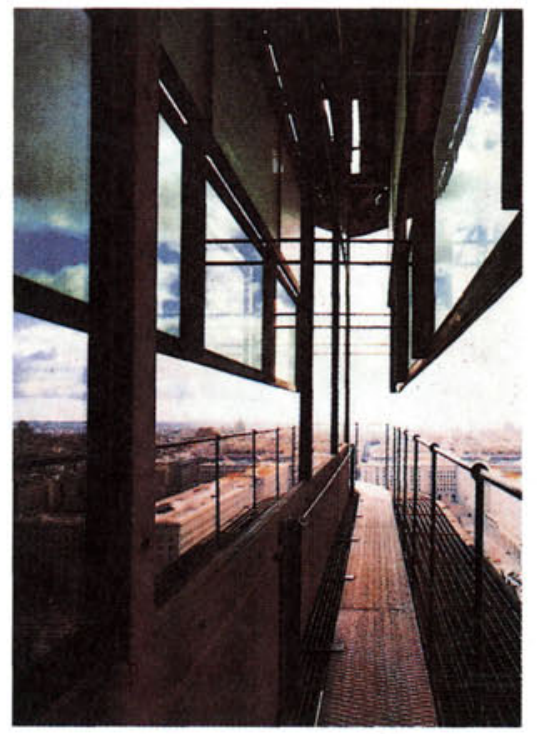




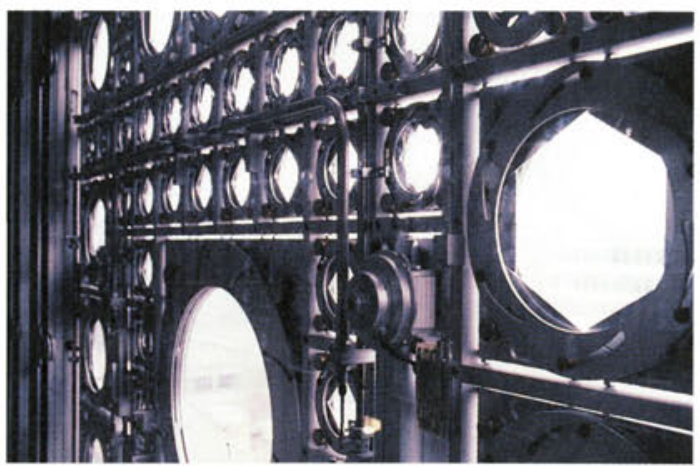

Instituto del Mundo

Arabe

Jean Nouvel, 1983/87
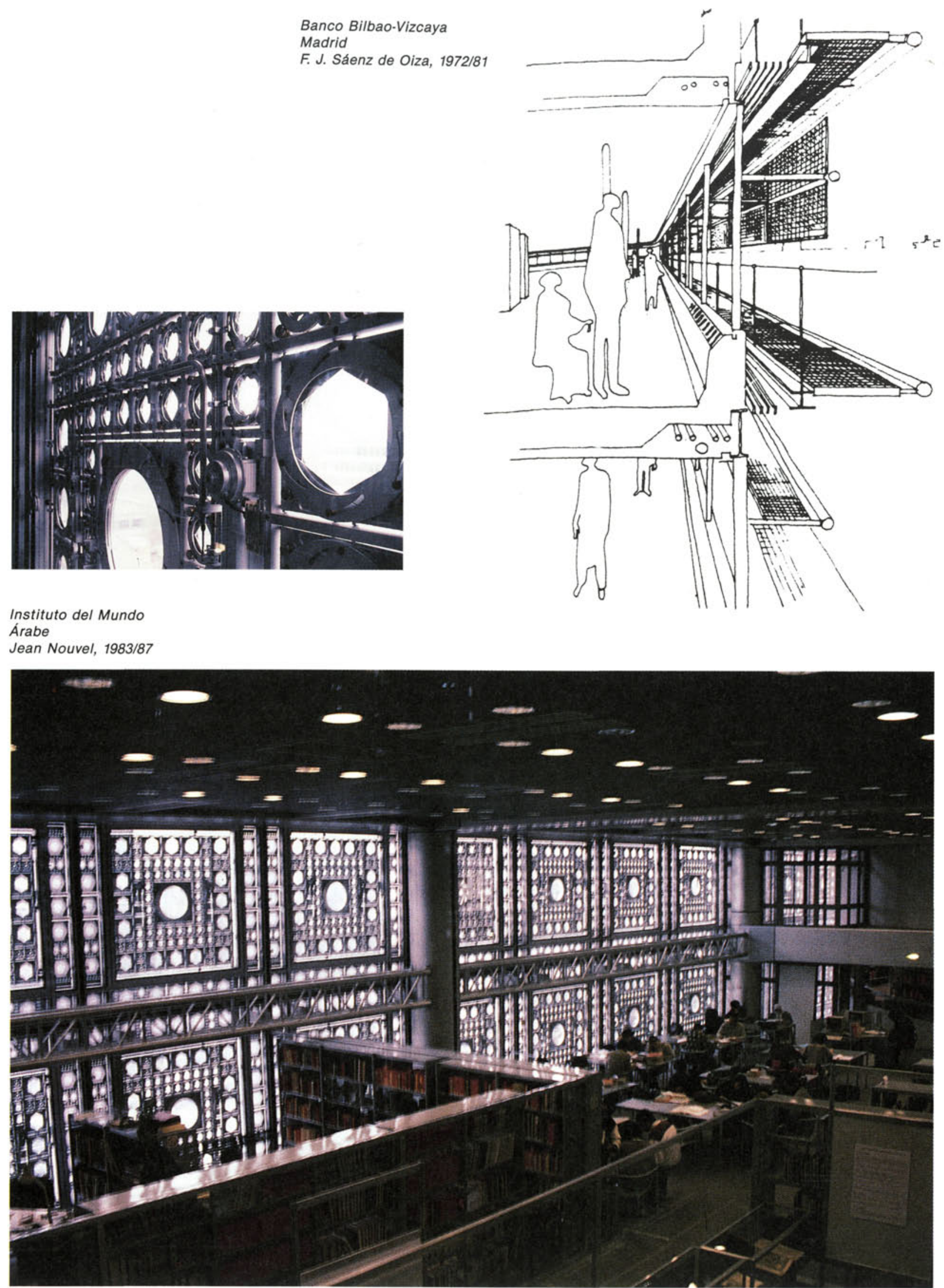
Por otra parte, esos cerramientos donde el límite se gradua y abre a la atmósfera nos ofrecen la posibilidad de convivir con y en la biosfera terrestre. ¿Por cuánto tiempo más podremos disfrutar de esa favorable situación? ¿Se volverá definitivamente agresiva la atmósfera terrestre para la vida?: agujero de ozono, aumento del nivel del mar, selvas quemadas, aumento de la desertización, efecto invernadero,...

Quizás, la gran diferencia entre estas dos opciones de arquitectura es el gasto energético para su mantenimiento: Una lo hace en simbiosis con la biosfera, la otra no. Una quiere adaptarse al espacio natural existente, la otra explora a través de la dimensión ideal del hombre... ...

Madrid, noviembre 1991

En el futuro, que las ciudades estarán climatizadas, el maquillaje ya no se limitará sólo a la cara, sino que se extenderá por todo el cuerpo, como una segunda piel. El vestido será un adorno, perderá sus limitaciones climáticas y se convertirá en una joya.

Pierre Cardin, 1991

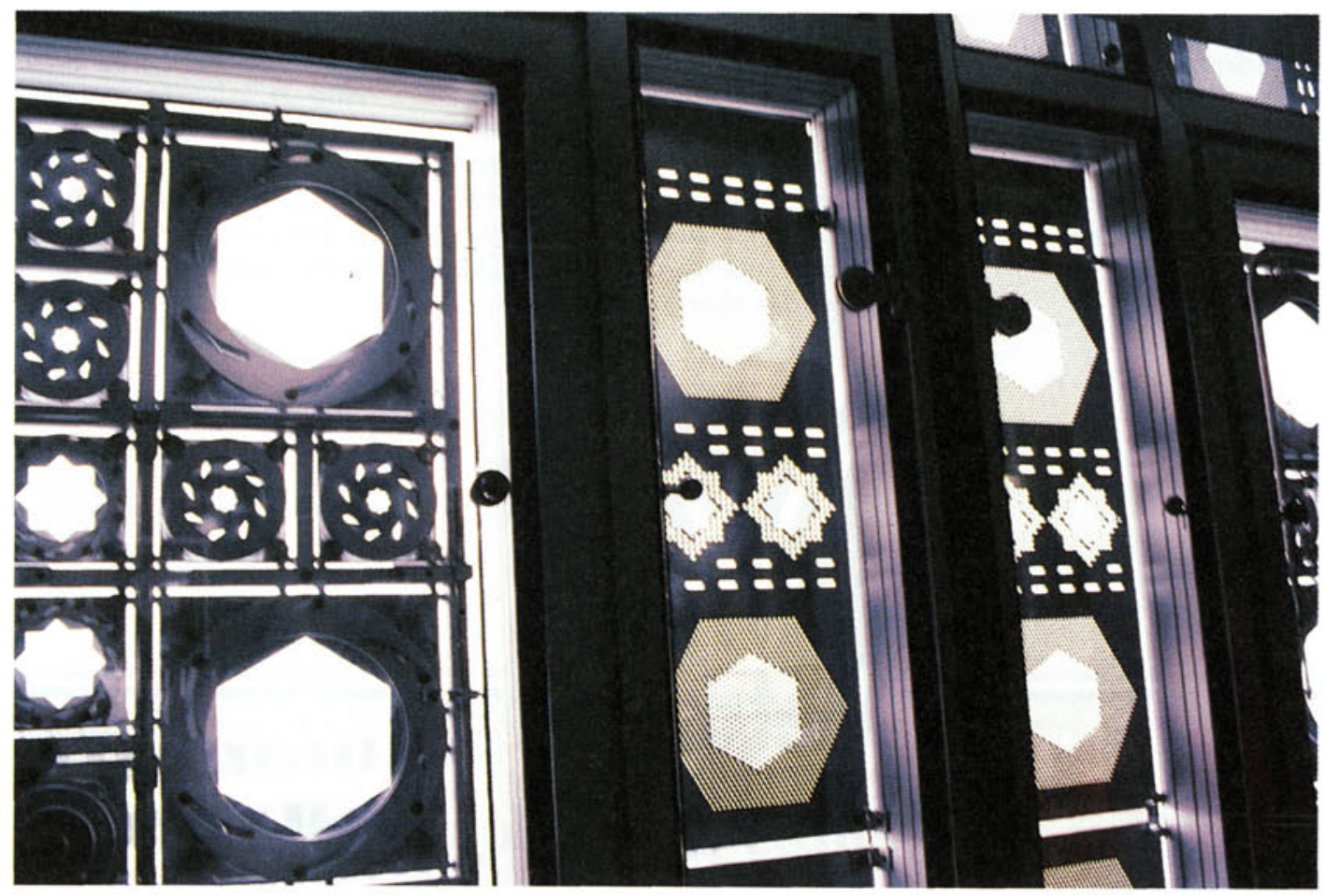

